\title{
С.В. Гречишкина
}

\section{ПРОЦЕСС ФОРМИРОВАНИЯ ЭКОЛОГИЧЕСКОЙ КУЛЬТУРЫ В США: АМЕРИКАНСКИЕ ЦЕННОСТИ}

\begin{abstract}
В статье анализируется процесс формирования экологической культуры США и его связь с системой американских иенностей. Основной целью статьи является объяснение того, почему, несмотря на то, что основной ценностью американской культуры является накопление материальных благ, в США существует достаточно развитая экологическая культура. Среди задач, решаемых в исследовании, выделяется определение факторов, которые обусловливают развитие экологического сознания в его антропоцентрическом и экочентрическом вариантах, а также выявление роли экологической литературы в формировании экологической культуры.

Ключевые слова: американские иенности, трансиендентализм, экологическая культуpa, экологическая литература, экологическое сознание.
\end{abstract}

Известно, что сегодня лидеры многих стран ведут переговоры, связанные с сокращением вредного влияния человеческой деятельности на природу. Одним из ключевых моментов в деле улучшения экологической обстановки в мире является формирование экологической культуры. Ещё в 70-е гг. прошлого столетия известные журналисты В. Песков и Б. Стрельников в своей книге «Земля за океаном», рассказывающей об их путешествии по США, отметили, что Америка имеет большой опыт воспитания культуры поведения людей в природе, значительный опыт заповедного дела, к которым нужно присмотреться, поскольку «землю надо беречь сообща» [1. С. 200]. Процесс формирования экологической культуры зависит, в частности, от системы национальных ценностей. По мнению известного политолога Н.В. Злобина, в условиях негативного восприятия США многими россиянами необходим объективный взгляд и «хорошее понимание политической и бытовой культуры американцев, их системы ценностей, жизненных ориентиров и желаний, логики мышления и поведения» [2]. Анализ процесса формирования экологической культуры поможет углубить наше понимание этой области.

Вопрос связи процесса формирования экологической культуры США с системой американских ценностей является достаточно сложным, поскольку для американской культуры характерно стремление к материальному благополучию, желание обладать как можно большим количеством вещей, что, с первого взгляда, не сочетается с пониманием самоценности природы. Исследователи (А. Нейс, Г.Д. Торо, Г. Снайдер и др.) говорят о необходимости смены антропоцентрической парадигмы и признание самоценности природы. Необходимо выяснить, что способствует развитию экоцентрического экологического сознания, в котором основной ценностью видится не человек, а вся экосистема. Данный тип сознания предполагает отказ от большого количества материальных благ ради спасения всей экосистемы.

Вопросами, связанными с изучением экологической культуры и экологического сознания, занимались С.Н. Глазачев, Е.Ю. Захарова, Т.В. Иванова, 
А.Н. Кочергин, И.В. Кряж, а также многие другие исследователи. Круг данных вопросов постоянно расширяется, отражая необходимость решения одной из главных проблем современности - нахождение способов гармоничного взаимодействия человека с остальным природным миром. Е.Л. Яковлева, О.В. Григорьева и Е.В. Байбакова определяют экологическую культуру как мировоззренческую систему взглядов, установок и ценностей, социальных отношений и этических норм, определяющих и регулирующих взаимоотношения человека и окружающего мира [3. С. 26]. В.А. Ситаров и В.В. Пустовойтов, основываясь на исследованиях Б.Т. Лихачёвой и В.А. Скребец, указывают на то, что неотъемлемым элементом экологической культуры является экологическое сознание, представляющее собой «высший уровень психического отражения природной и искусственной среды, своего внутреннего мира, рефлексию места и роли человека в биологическом, физическом и химическом мире, а также саморегуляцию данного отражения» [4. С. 91-93]. Экологическое сознание может быть антропоцентрическим и экоцентрическим. С.Д. Дерябло и В.А. Ясвин, выделяя признаки, присущие данным типам, указывают, что антропоцентрический тип видит целью взаимодействия с природой «удовлетворение тех или иных прагматических потребностей», а экоцентрический - «оптимальное удовлетворение как потребностей человека, так и потребностей всего природного сообщества» [Там же. С. 91]. Именно второй тип экологического сознания необходимо развивать для сохранения целостности экосистем и торможения процесса изменения климата.

Многие исследователи, как российские, так и американские, говорят о сохранении в западных странах, в том числе в США, антропоцентрической парадигмы, затрудняющей распространение экологических ценностей. Например, М.Ю. Шишин говорит о кризисе техногенно-потребительской модели мирового развития, господствовавшей на протяжении нескольких веков и наиболее ярко проявившей себя в развитых странах Запада [5]. Д.Дж. Пейн утверждает, что вместо стремления к гармоничному сосуществованию с окружающей средой многие американцы до сих пор относятся к ней с позиций антропоцентризма, предполагающего восприятие окружающей среды как бездонного источника ресурсов [6. Р. 2]. Необходимо разобраться, на самом ли деле в США развивается лишь антропоцентрический тип экологического сознания и какие факторы способствуют развитию экоцентрического типа экологического сознания. Отношение людей к природе, несомненно, связано с системой национальных ценностей, поэтому ниже дан краткий обзор системы ценностей США.

Несмотря на достаточно короткую историю существования США, у американцев сформировалась устойчивая система национальных ценностей. Например, Н.В. Злобин указывает, что подавляющему большинству населения страны присущ один набор ценностей, несмотря на различия в ценностных ориентирах между социальными группами [2]. О существовании единой системы ценностей говорится также в монографии Л.Р. Коулза «Ценности, которыми живут американцы». В ней Коулз выделяет такие характерные для американцев ценности, как личный контроль над обстоятельствами, ценность личного пространства, частной жизни, ценность перемен, время и умение его распределять, равенство, индивидуализм, свободное предпринимательство, ориентация на будущее, активная деятельность и работа, материализм, при- 
обретение вещей и др. [7]. Э. Стил и Ч. Риддинг в статье «Система ценностей американцев: вопросы убеждения» выделяют такие ценности, как моральные ценности пуритан, успех, нацеленность на результат, перемены и прогресс, равенство, усилие и оптимизм, а также индивидуализм [8]. В 2012-2014 гг. были проведены социологические опросы, целью которых было выявление современных ценностей американцев [9-11]. Среди ценностей, которые американцы считают превосходящими ценности остальных наций, американцы выделили свободу слова (67\%), свободу вероисповедания (61\%), принцип равенства (50\%), способность адаптироваться к переменам (46\%), христианство (40\%) и некоторые другие [9].

В передаче «Говорите с Америкой» радиостанции «Голос Америки», посвящённой американским ценностям, которая вышла в июле 2005 г., упоминалось, что идеалы американского общества являются результатом исторического прошлого страны и религиозной принадлежности американцев [12]. В основу системы ценностей американцев была положена англопротестантская культура. Н.В. Злобин отмечает, что США на сегодняшний день являются самой религиозной из всех развитых экономик мира [2]. Это значит, что отношение американцев к природе до сих пор во многом обусловлено религией.

В конце 90-Х гг. ХХ в. 70\% американцев причисляли себя к протестантам [13. С. 9-15]. Известный российский политолог В.Ю. Крашенниникова поясняет, что «американский протестантизм обрёл видение труда и получения прибыли от него как знак избранности» [14. С. 111]. Американский исследователь Л. Уайт в своей работе «Исторические корни нашего экологического кризиса» указывает, что западный вариант христианства, являясь одной из самых антропоцентрических религий мира, послужил причиной экологического кризиса, дав людям уверенность в превосходстве над природой, не имеющей, согласно данной религии, души или разума [15]. Соответственно эксплуатация природных ресурсов изначально не носила в глазах американцев негативного значения, поскольку бог, по их мнению, предоставил им право посредством труда и использования имеющихся у них природных ресурсов обретать материальное благополучие.

Повлияла на восприятие природы американцами и территория их проживания. О связи национального характера и занимаемой нацией территории упоминал ещё Н.А. Бердяев. Например, говоря о русской душе, Бердяев утверждал, что она «ушиблена ширью», безграничностью русского государства и безграничностью русских полей. Русский человек, по мнению Бердяева, чувствует свою неспособность овладеть огромными пространствами и организовать их, поскольку привык «возлагать эту организацию на центральную власть, как бы трансцендентную для него» [16. С. 63]. В противоположность русским американцы старались овладеть природой, контролировать её, организовывая согласно своим желаниям. Этому способствовали такие ранее упомянутые ценности американской культуры, как контроль над обстоятельствами, индивидуализм и активная деятельность.

Природа, в частности земля, в США воспринималась как нечто, что можно поделить и использовать в целях личного обогащения, как нечто, подлежащее упорядочиванию и контролю. Исследователи Н. Кэмпбелл и А. Кин указывают, например, что на Западе, регионе, считавшемся основным пока- 
зателем того, как нация воспринимала себя, очень часто использовали в искусстве образ сексуального насилия, завоевания «девственной земли» [17. Р. 147]. Образ, создаваемый в массовой культуре, отчасти соответствовал образу, создаваемому президентами США в своих выступлениях.

Земля и даже космос в целом, по мнению президентов США, должны быть покорены, причём Америка должна была лидировать в деле контроля над природой. В своей речи «Полёт на Луну» Кеннеди заявил, что с благословения господа бога американцы готовы овладеть новым знанием, скрытым в космосе [18]. Кеннеди среди прочих использовал глагол climb, в одном из значений подразумевающий достижение вершины посредством использования рук [19]. Овладение знаниями Кеннеди связал с установлением мира. Очевидно, что в сознание американской нации вкладывалась идея о том, что американцы должны лидировать в области науки, чтобы, владея знаниями, владеть миром, устанавливая в нём свой порядок.

Современные социологические опросы показывают, что американцы стали всё чаще задумываться о своём воздействии на природу. На вопрос о существовании или отсутствии изменения климата, а также видимых его результатах 49\% американцев ответили, что изменение климата - неоспоримый факт, при этом 41\% верят, что причиной изменения является деятельность человека [10]. 54\% опрошенных в 2014 г. были уверены, что через 10 лет изменение климата станет более заметным, а 26\% затруднились ответить на этот вопрос [11]. Исследование также показало, что 20\% опрошенных полагают, что купят электромобиль [11]. Это говорит о заинтересованности американцев в улучшении экологической обстановки в стране.

Защитники природы прикладывают немало усилий, чтобы добиться развития экологической культуры. Достаточно информативным источником об их деятельности и развитии экологической культуры США является книга Р. Нэша «Дикая природа и американский разум» [20]. Факты, изложенные в данной книге, позволяют выделить 6 этапов развития экологической культуры США: 1-й этап - заселение территории европейскими поселенцами, образование США, когда дикая природа противопоставлялась раю; 2-й этап эпоха Романтизма, когда трансценденталисты дикую природу считали обиталищем божественного духа; 3-й этап - середина XIX в., ознаменовавшаяся активизацией природоохранного движения; 4-й этап - конец XIX - начало $\mathrm{XX}$ в., когда природоохранное движение приобрело массовый характер, а также появился научный базис этого движения; 5-й этап - 60-е гг. XX в., характеризующиеся образованием контркультуры, призывающей к отказу от некоторых традиционных ценностей американской культуры и к рассмотрению природы как субъекта, обладающего внутренней ценностью; 6-й этап конец XX - начало XXI в., когда экологическая культура получила достаточно широкое распространение.

Большое значение для развития экологической культуры в США и отказа от материализма имело мощное движение трансцендентализма, сторонники которого воспринимали природу как одухотворённую сущность. Трансцендентализм был толчком к пониманию взаимосвязи между местом проживания и человеком, которое легло в основу многих литературных произведений [21. Р. 54]. Трансценденталисты в отличие от пуритан верили, что дикая природа не представляет опасности, поскольку считали, что человеку изначально 
присуща доброта. Что более важно, они верили, что именно возвращение к дикой природе поможет достичь морального совершенства [21. Р. 24]. Такие взгляды способствовали развитию экоцентрического типа экологического сознания.

Особое понимание природы трансценденталистами является результатом их внимания к буддизму. Известно, что первая волна иммигрантов-буддистов пришлась в США на 1840-е. В журнале трансценденталистов The Dial («Циферблат») был опубликован священный буддийский текст, переведённый на английский язык [22. Р.51]. Сильное увлечение буддизмом пришлось на 1950-е, когда Джек Керуак и другие члены движения битников популяризировали произведения японского исследователя дзэн-буддизма Д.Т. Судзуки. На сегодняшний день в США насчитывается около 2-3 млн буддистов [Ibid. Р. 47]. Можно утверждать, что некоторые идеи буддизма вошли в экологическую культуру США посредством литературы и повседневного влияния культуры иммигрантов из Азии на культурное ядро страны.

О распространении экологических ценностей в американской культуре говорит принятие законодательных актов, направленных на защиту окружающей среды. Одним из них является закон США «О дикой природе», принятый в 1964 г. [23]. Н.В. Злобин отмечает, что «закон в Америке пользуется не только почти абсолютным уважением, но и является в определенном смысле сакральным явлением [2]. Соответственно готовность американцев строго соблюдать законы по защите природного сообщества, способствующие гармоничному взаимодействию человека с остальными представителями природного мира, влияет на развитие экоцентрического экологического сознания. В 2015 г. американский суд признал право на свободу двух шимпанзе, над которыми проводили эксперименты в одном из университетов США [24]. Таким образом, постепенно права, гарантированные изначально только людям, распространяются и на других представителей природного мира.

Ещё одним из факторов развития экоцентрического сознания, на наш взгляд, является патриотизм американцев. В книге «Земля за океаном» отмечается, что «патриотизм американцев - понятие почти осязаемое» [1. С. 193]. Н.В. Злобин, проживший много лет в США, утверждает, что «здоровый патриотизм по отношению к стране, обществу, своим идеалам всегда был и остаётся здесь частью системы ценностей, прививаемых с детства» [2]. Патриотизм помог американцам приложить немалые усилия в сохранении природных богатств страны. Например, в 1872 г. был создан Йеллоустонский национальный парк, явившийся первым в мире национальным парком. Сейчас в США насчитывается 58 национальных парков, а в России на 2013 г. их было 46.

На территории США действуют многие природоохранные организации. Это, например, всем известная международная организация «Гринпис», а также организация «Земля прежде всего!» (Earth First!), являющаяся одной из самых радикальных организаций, чья деятельность связана с защитой природы. Данное движение было вдохновлено произведением Э. Эбби «Банда разводного ключа» (1975), в котором рассказывается об экотаже, или экотерроризме [25].

Д.Дж. Пейн в целом акцентирует внимание на том, что импульсом к развитию экологической культуры в США послужила экологическая литература, 
в частности, произведения Джона Барроуза, Рейчел Карсон, Олдо Леопольда, Джорджа Перкинса Марша, Джона Мьюира, Генри Дэвида Торо и других авторов [6. Р. 2]. Писатели задавали темы для обсуждения, собирали доводы в пользу формирования экологической культуры, привлекали внимание общественности к экологическим проблемам.

Барри Лопес, лауреат Национальной книжной премии США, утверждает, что экологическая литература и сегодня имеет большое влияние на развитие взаимоотношений человека с природой, являясь одним из эффективных способов борьбы против разрушительных действий капиталистического производства, сговора правительства и представителей бизнеса, а также разрушения демократических принципов США [26]. В США главной проблемой, затрагиваемой экологической литературой, является проблема духовного упадка западной культуры, связанная с национализмом и огромным вниманием к материальным ценностям [27]. Основное внимание в экологической литературе сосредоточено не просто на природе, а на проблемах взаимодействия человека с природой, возникающих из-за непонимания человеком своей неразрывной связи с природой.

Сегодня американские политики публично признают негативное влияние деятельности человека на окружающую среду. Известно, например, что Б. Обама подписал Парижское соглашение в 2015 г., призванное предотвратить рост температуры в мире на 2 градуса за счёт снижения выброса парниковых газов и развития экологически чистых источников энергии, а также проводил финансирование данного соглашения [28]. Однако Д. Трамп заявил о выходе из Парижского соглашения и прекращении его финансирования, поскольку он считает, что данное соглашение послужит причиной снижения экономической мощи США и увеличения мощи других стран [29]. Такая позиция американского президента отражает тенденцию к сохранению антропоцентрического типа экологического сознания, при котором отмечается приоритет удовлетворения экономических потребностей человека. Несмотря на решение США, лидеры стран Большой двадцатки на саммите в Гамбурге в начале июля 2017 г. выразили своё намерение ратифицировать Парижское соглашение. В коммюнике по итогам саммита говорится, однако, что США «подтверждает твёрдую приверженность к подходу, который снижает выбросы [углекислого газа] при поддержке экономического роста и улучшает энергетическую безопасность» [30]. В будущем станет ясно, насколько плодотворным является такой подход без участия в международных соглашениях.

Итак, о развитии экологической культуры в США говорят деятельность природоохранных организаций, принятие законодательных актов, защищающих природу, публичное признание наличия глобального потепления, вызванного деятельностью человека, сотрудничество с другими странами в области разработки экологически чистых источников энергии, а также некоторые другие признаки. Природа, в частности земля, в США долгое время воспринималась как источник личного обогащения. Стремление к накоплению материальных благ, ассоциирующееся у американцев со счастьем, привело к развитию антропоцентрического экологического сознания. Экоцентрическое экологическое сознание формировалось благодаря деятельности отдельных активистов, эколитературных произведений. Среди факторов, способствовавших развитию экоцентрического типа экологического созна- 
ния, можно выделить такие ценности, как патриотизм и готовность соблюдать законы.

\section{Литература}

1. Песков В., Стрельников Б. Земля за океаном. М.: Молодая гвардия, 1975. 288 с.

2. Злобин Н. В. Империя свободы: ценности и фобии американского общества. М.: Эксмо, 2016. 480 c. RuLit URL: http://www.rulit.me/books/imperiya-svobody-cennosti-i-fobiiamerikanskogo-obshchestva-read-455211-14.html (дата обращения: 09.07.2017).

3. Яковлева Е.Л., Григорьева О.В., Байбакова Е.В. Экологическая культура. Казань: Изд-во «Познание» Института экономики, управления и права, 2014. 192 с.

4. Ситаров B.A., Пустовойтов B.B. Социальная экология: учеб. пособие для студ. высш. пед. учеб. заведений. М.: Академия, 2000. 280 с.

5. Шишин М.Ю. Ценностно-мировоззренческие основания экологической культуры // Формирование экологической культуры и развитие молодёжного движения / под ред. В.М. Захарова. М.: Акрополь, Центр экологической политики и культуры, Центр экологической политики России, 2008. С. 37-43.

6. Payne D.G. Voices in the Wilderness: American Nature Writing and Environmental Politics. Hanover and London: University Press of New England, 1996.

7. Kohls L.R. The Values Americans Live By. URL: http://www1.cmc.edu/pages/faculty/alee/extra/American_values.html (дата обращения: 01.02.2017).

8. Steele E.D., Red ding W.C. The American Value System: Premises for Persuasion. URL: $\mathrm{http}$ //changingminds.org/explanations/values/american_values.htm (дата обращения: 20.01.2017).

9. Penn M. Americans Are Losing Confidence in the Nation but Still Believe in Themselves // The Atlantic. URL: http://www.theatlantic.com/national/archive/2012/06/americans-are-losingconfidence-in-the-nation-but-still-believe-in-themselves/259039/ (дата обращения: 15.01.2017).

10. Cohn B. The Divided States of America, in 25 Charts // The Atlantic. URL: http://www.theatlantic.com/national/archive/2013/06/the-divided-states-of-america-in-25-charts/277303/ (дата обращения: 15.01.2017).

11. Graham D.A. What Will America Look Like in 2024 // The Atlantic. URL: http://www.theatlantic.com/politics/archive/2014/07/what-americans-expect-over-the-next-10-yearsin-tk-charts/373610/ (дата обращения: 15.01.2017).

12. Американские идеалы и ценности // Голос Америки. URL: http://www.golosameriki.ru/a/a-33-2005-07-09-voa8/632983.html (дата обращения: 17.01.2017).

13. Weaver G.R. American Cultural Values // Kokusai Bunka Kenshu (Intercultural Training), 1999. Pp. 9-15. URL: http://trends.gmfus.org/doc/mmf/American\%20Cultural\%20Values.pdf (дата обращения: 12.01.2017).

14. Крашенниникова В.Ю. Россия - Америка: «холодная война» культур. Как американские ценности преломляют видение России. М.: Европа, 2007. 396 с.

15. White L. The historical roots of our ecologic crisis // Readings in biology and man. 1967. URL: https://books.google.ru/ (дата обращения: 10.07.2017).

16. Бердяев Н.А. О власти пространств над русской душой // Электронная библиотека Одинцовского Благочиния. URL: http://odinblago.ru/vlast prostranstv (дата обращения: 20.01.2017).

17. Campbell N., Kean A. American Cultural Studies. An Introduction to American Culture. London and New York: Routledge, 2005. 303 p.

18. Kennedy J.F. To the Moon. URL: http://www.emersonkent.com/speeches/to_the_moon.htm (дата обращения: 21.01.2017).

19. Merriam-Webster Dictionary. URL: https://www.merriam-webster.com/dictionary/climb (дата обращения: 25.01.2017).

20. Нэш Р. Дикая природа и американский разум / сокращ. пер. с англ. С. Колоса, В. Борейко. Киев: Киевский эколого-культурный центр, 2004. 205 c. URL: http://www.gumer.info/bibliotek_Buks/Culture/Nash/intro.php (дата обращения: 20.01.2017).

21. The Cambridge Companion to Modern American Culture / ed. Ch. Bigsby. Cambridge University Press, 2006. 496 p.

22. Prothero $S$. Buddhism in America // Religion and American Cultures. An Encyclopedia of Traditions, Diversity, and Popular Expressions. Vol. 1 / ed. G. Laderman, L. Leon. Santa Barbara: ABC-CLIO, Inc., 2003. P. 47-55. 
23. The Wilderness Act of 1964 // Wilderness.net. URL: http://www.wilderness.net/nwps/legisact (дата обращения: 17.01.2017).

24. Vegan. URL: http://veganstvo.info/313-v-sha-priznali-nalichie-prav-shimpanze.html (дата обращения: 08.07.2017).

25. Earth First. URL: http://earthfirstjournal.org/ (дата обращения: 20.01.2017).

26. Lopez B. A Literature of Place. URL: http://arts.envirolink.org/literary_arts/BarryLopez_LitofPlace.html (дата обращения: 25.01.2017).

27. Lopez B. Introduction to Nature Writing. URL: http://lopezbooks.com/catalog/n/static/ (дата обращения: 25.01.2017).

28. Slezak M. Barack Obama transfers $\$ 500 \mathrm{~m}$ to Green Climate Fund in attempt to protect Paris deal // The Guardian. URL: https://www.theguardian.com/us-news/2017/jan/18/barack-obamatransfers-500m-to-green-climate-fund-in-attempt-to-protect-paris-deal (дата обращения: 12.02.2017).

29. The White House. URL: https://www.whitehouse.gov/the-press-office/2017/06/01/statementpresident-trump-paris-climate-accord (дата обращения: 03.07.2017).

30. TACC. URL: http://tass.ru/mezhdunarodnaya-panorama/4398932 (дата обращения: 10.07.2017).

Grechishkina Svetlalna $\boldsymbol{V}$. Transbaikal State University (Chita, Russian Federation).

E-mail: Sveta-only4me@mail.ru

Tomsk State University Journal of Cultural Studies and Art History, 2018, 30, pp. 33-42.

DOI: $10.17223 / 2220836 / 30 / 4$

THE PROCESS OF ECOLOGICAL CULTURE FORMATION IN THE USA: AMERICAN VALUES

Keywords: American values; Anglo-protestant culture; ecological culture; ecological literature; Transcendentalism.

The author of the article analyzes the way in which the formation of US ecological culture is interlinked with the development of American values system. This question is complex, because Americans are characterized by their desire to be wealthy and the desire to obtain as many things as they can. And that feature is not compatible with ecological ethics and the intrinsic value of nature. American culture is rooted in Protestantism which means that Americans see material wealth as a just reward for hard work. That means that Americans are reluctant to reject material wealth. Americans have considered nature being a source of this wealth as something which must be controlled. The process of the ecological culture formation has been slow because the basis of ecological culture mainly contradicts the US cultural values.

Environmentalists have to put much effort into stimulating the process of ecological culture development. We can single out 6 steps of the process of US ecological culture development basing on the research of Roderick Nash. The first step is European colonization of North America and the formation of the USA when nature was perceived to be the opposite of Eden. The second step is the era of Romanticism when Transcendentalists considered that nature was divine. The third step is the middle of the $19^{\text {th }}$ century marked by the increase of the number of environmentalists and the intensity of their activity. The fourth step embraces the period from the end of the $19^{\text {th }}$ till the beginning of the $20^{\text {th }}$ century when the conservation movement became a significant one and obtained a scientific basis. The fifth step is 1960s characterized by the formation of counterculture calling to the rejection of traditional American values and reconsideration of nature as an active subject having intrinsic value. The last step embraces the period from the end of the $20^{\text {th }}$ till the beginning of the $21^{\text {st }}$ century when ecological culture has become wide-spread.

The development of ecological culture was stimulated by literary works and social activity of such authors as Henry Davis Thoreau, John Muir, Aldo Leopold, Rachel Carson, etc. The authors initiated the discussion of certain issues, gave the reasons to carry out ecological reform and attracted the attention of American masses. Thus, the process of US ecological culture development has been highly dependent on ecological literature proliferation. The attention of ecological literature focuses on not only nature itself, but on the problems of human-nature relationship, on the problems caused by the fact that humans do not understand that they are an integral part of nature.

American values system has been changing. US ecological culture development has resulted in adopting the laws protecting nature, public acceptance of the fact that human activity has a negative effect on the environment and the fact of the existence of global warming caused by the human activity. One more indicator of US ecological culture development is signing international agreements 
aimed at reducing the negative impact of humans on the environment. Americans have been slowly accepting ecological values.

\section{References}

1. Peskov, V. \& Strelnikov, B. (1975) Zemlya za okeanom [Earth Beyond the Ocean]. Moscow: Molodaya gvardiya.

2. Zlobin, N.V. (2016) Imperiya svobody: tsennosti i fobii amerikanskogo obshchestva [Empire of Freedom: Values and Phobias of American Society]. Moscow: Eksmo.

3. Yakovleva, E.L., Grigorieva, O.V. \& Baibakova, E.V. (2014) Ekologicheskaya kul'tura [Ecological Culture]. Kazan: Poznaniye.

4. Sitarov, V.A. \& Pustovoytov, V. V. (2000) Sotsial'naya ekologiya [Social Ecology]. Moscow: Akademiya.

5. Shishin, M.Yu. (2008) Tsennostno-mirovozzrencheskiye osnovaniya ekologicheskoy kul'tury [Axiological bases of ecological culture]. In: Zakharov, V.M. (ed.) Formirovaniye ekologicheskoy kul'tury i razvitiye molodozhnogo dvizheniya [Formation of ecological culture and development of youth movement]. Moscow: Akropol', Tsentr ekologicheskoy politiki i kul'tury. pp. 37-43.

6. Payne, D. G. (1996) Voices in the Wilderness: American Nature Writing and Environmental Politics. Hanover \& London: University Press of New England.

7. Kohls, L.R. (n.d.) The Values Americans Live By. [Online] Available from: http://www1.cmc.edu/pages/faculty/alee/extra/American_values.html. (Accessed: 1st February 2017).

8. Steele, E.D. \& Redding, W.C. (n.d.) The American Value System: Premises for Persuasion. [Online] Available from: http://changingminds.org/explanations/values/american_values.htm. (Accessed: 20th January 2017).

9. Penn, M. (2012) Americans Are Losing Confidence in the Nation but Still Believe in Themselves. [Online] Available from: http://www.theatlantic.com/national/archive/2012/06/americans-arelosing-confidence-in-the-nation-but-still-believe-in-themselves/259039/. (Accessed: 15th January 2017).

10. Cohn, B. (2013) The Divided States of America, in 25 Charts. [Online] Available from: http://www.theatlantic.com/national/archive/2013/06/the-divided-states-of-america-in-25-

charts/277303/. (Accessed: 15th January 2017).

11. Graham, D.A. (2014) What Will America Look Like in 2024. [Online] Available from: http://www.theatlantic.com/politics/archive/2014/07/what-americans-expect-over-the-next-10-yearsin-tk-charts/373610/. (Accessed: 15th January 2017).

12. Goble, P. (2005) Amerikanskiye idealy $i$ tsennosti [American ideals and values]. [Online] Available from: http://www.golos-ameriki.ru/a/a-33-2005-07-09-voa8/632983.html. (Accessed: 17th January 2017).

13. Weaver, G.R. (1999) American Cultural Values. [Online] Available from: http://trends.gmfus.org/doc/mmf/American\%20Cultural\%20Values.pdf. (Accessed: 12th January 2017).

14. Krashenninikova, V.Yu. (2007) Rossiya - Amerika: kholodnaya voyna kul'tur. Kak amerikanskiye tsennosti prelomlyayut videniye Rossii [Russia - America: the Cold War of Cultures. How American values refract the vision of Russia]. Moscow: Yevropa.

15. White, L. (1967) The historical roots of our ecologic crisis. In: Santos, M.A. Readings in Biology and Man. Ardent Media. [Online] Available from: https://books.google.ru/. (Accessed: 10th July 2017).

16. Berdyayev, N.A. (n.d.) O vlasti prostranstv nad russkoy dushoy [The Power of Spaces over the Russian Soul]. [Online] Available from: http://odinblago.ru/vlast_prostranstv. (Accessed: 20th January 2017).

17. Campbell, N. \& Kean, A. (2005) American Cultural Studies. An Introduction to American Culture. London; New York: Routledge.

18. Kennedy, J.F. (n.d.) To the Moon. [Online] Available from: http://www.emersonkent.com/speeches/to_the_moon.htm. (Accessed: 21st January 2017).

19. Merriam-Webster Dictionary. (n.d.) [Online] Available from: https://www.merriamwebster.com/dictionary/climb. (Accessed: 25th January 2017).

20. Nesh, R. (2004) Dikaya priroda i amerikanskiy razum [Wildlife and American Mind]. Translated from English by S Kolos, V. Boreyko. Kyiv: Kiyevskiy ekologo-kul'turnyy tsentr. [Online] Available from: http://www.gumer.info/bibliotek_Buks/Culture/Nash/intro.php. (Accessed: 20th January 2017). 
21. Bigsby, Ch. (ed.) (2006) The Cambridge Companion to Modern American Culture. Cambridge University Press.

22. Prothero, S. (2003) Buddhism in America. In: Laderman, G. \& Leon, L. (eds) Religion and American Cultures. An Encyclopedia of Traditions, Diversity, and Popular Expressions. Vol. 1. Santa Barbara: ABC-CLIO, Inc. pp. 47-55.

23. Wilderness.net. (n.d.) The Wilderness Act of 1964. [Online] Available from: http://www.wilderness.net/nwps/legisact. (Accessed: 17th January 2017).

24. Veganstvo.info. (2015) V SSHA priznali nalichiye prav u shimpanze [The United States recognized the existence of rights for chimpanzees]. [Online] Available from: http://veganstvo.info/313v-sha-priznali-nalichie-prav-shimpanze.html. (Accessed: 8th July 2017).

25. Earth First. (n.d.) [Online] Available from: http://earthfirstjournal.org/. (Accessed: 20th January 2017).

26. Lopez, B. (n.d.) A Literature of Place. [Online] Available from: http://arts.envirolink.org/literary arts/BarryLopez LitofPlace.html. (Accessed: 25th January 2017).

27. Lopez, B. (n.d.) Introduction to Nature Writing. [Online] Available from: http://lopezbooks.com/catalog/n/static/. (Accessed: 25th January 2017).

28. Slezak, M. (2017) Barack Obama transfers $\$ 500 m$ to Green Climate Fund in attempt to protect Paris deal. [Online] Available from: https://www.theguardian.com/us-news/2017/jan/18/barackobama-transfers-500m-to-green-climate-fund-in-attempt-to-protect-paris-deal. (Accessed: 12th February 2017).

29. Trump, D. (2017) Statement by President Trump on the Paris Climate Accord. [Online] Available from: https://www.whitehouse.gov/the-press-office/2017/06/01/statement-president-trumpparis-climate-accord. (Accessed: 3rd July 2017).

30. Klimentiev, M. (2017) Lidery stran G20 prinyali kommyunike po itogam sammita v Gamburge [The G20 Leaders adopted a communique on the results of the Hamburg summit]. [Online] Available from: http://tass.ru/mezhdunarodnaya-panorama/4398932. (Accessed: 10th July 2017). 